\title{
Clean energy projects in growing economies - external regulatory factors of path dependence
}

\author{
Ivan M. Sekulovic \\ Belgrade, Serbia \\ ivan.sekulovic82@gmail.com
}

\begin{abstract}
Increased need for energy and, at the same time, increased environmental concern lead to a growing number of clean energy projects. This is especially noticeable on the example of growing economies However, these projects as organizational forms, performed under international agreement and its mechanisms of implementation, lead to path-dependent outcomes. Although the projects organized in project networks lead to path-dependent outcomes due to persistence and routines, there is also significant influence from the external factors such as regulatory ones.
\end{abstract}

Keywords-path dependence, project management regulatory environment, CDM mechanisms, clean energy.

\section{INTRODUCTION}

Modern growing economies in the world have been already heavily industrialized. The high-rate industrial development of those countries causes great spending on traditional energy and energy resources as well as serious climate change problems. Many countries by themselves or under international programs (such as JI or CDM mechanisms) try to find new sources of energy. Majority of growing economies are signees of Kyoto Protocol. Since they are not signees of Annex I, many of them can be host countries of CDM (Clean Development Mechanism) Projects. Such projects can be performed by residents of the host countries or by foreign or multinational actors as well. CDM projects have been criticized that they diffuse and push mature technologies [1], making the environment for pathdependent outcomes.

This research is based on Path Dependence Theory set by P. David in 1985. This theory has been attracting the interest of many scientists in the field of economics and management for a long time. Many efforts have been made to explain the factors creating path dependence as well as to forecast the outcomes of pathdependent processes. Path dependence and pathdependent processes came into focus of studying organizational processes as well. Among studied organizational processes through the lens of path dependence, significant place belongs to projects. Project-based organizing in recent period is welcomed by modern organizations. The reason for that is high level of flexibility that such organization model offers. Despite this increased need for more flexible structures and the substantial potential of the respective organizational forms such as projects and networks, there is at very same time an urgent demand for continuity in and across organizations so that economic activities can be carried out in an efficient and reliable way [2]. Demand for continuity and stability in projects may easily turn into routine and through selfreinforcing mechanisms lead to path-dependent outcomes. Still, path dependence can also be a deliberately chosen strategy of carrying out of project. On the other hand, there also are certain external mechanisms that may create path-dependent outcomes.

Renewable energy implementation projects that are carried out under Kyoto Protocol Mechanisms often lead to path-dependent outcomes.

The external factors that influence Kyoto Protocol CDM projects, especially regulatory ones, are examined through the theoretical approach.

\section{THEORETICAL BASE}

\section{Path Dependence Theory}

Path dependence theory was established by $\mathrm{P}$. David 1985. This theoretical concept is being increasingly present in modern social sciences. Path dependence concept appeared as a result of a historical quest for reasons and causes of today or future decisions and actions. Originally, there was an idea that some random shocks or initial advantage had been able to change history [3]. In modern social scientific disciplines, path dependence is one of the main tools for studying process of change and change management. Notions of change and change management imply that path dependence is closely related to dynamic processes. The dynamic processes are present in a wide range of scientific disciplines. Hence, the concept of path dependence can cover various fields, such as evolutionary biology, physics, technology, economics, etc. In other words, path dependence concept can be related to choice of technology solution, economic model or government policy, or any other appearances in physics, biology etc. The common denominator for all them is history.

The initial point for the vast majority of interpretations of the path dependence theory is the expression "history matters". However, both the expression and the very concept of path dependence are rather wide in their meaning. The expression "history matters" is too general in its scope and gives no precise meaning about the way of the influence of history. In other words, it does not answer the question how history influences our decisions or actions in the 
present. An acceptable definition of such relation was given by P. David: “...a dynamic process whose evolution is governed by its own history is pathdependent" [4]. Sometimes past decisions and actions may cause opposite decisions or actions in the present.

One of the most important business implications of path dependence theory is the phenomenon of lock-in. Lock-in effect is explained in various ways. Perhaps one of the most employed definitions is that lock-in means that one choice or action becomes better than any other because a sufficient number of people have already made that choice [5]. For David and Arthur, the term lock-in means "a vivid way to describe the entry of a system into a trapping region - the basin of attractions that surrounds a locally (or globally) stable equilibrium" [6]. However, "the entry of a system into a trapping region" usually associates the lock-in to inefficiency. Indeed, in modern economics and management, the term lock-in is almost always linked to the inefficiency. Escape from it is only possible through the intervention of some external force or shock that laters its configuration or transforms the underlying structural relationships among the agents [6].

In traditional literature about path dependence, the lock-in is treated as, in a way, a point of no return. Once we are locked-into a certain solution it is almost impossible to change it. This position is one of the main targets of path dependence theory critics. If David and Arthur usually connect lock-in with something inefficient and bad, their critics state that path dependence is not necessarily linked to bad and inefficient outcomes. Liebowitz and Margolis differ three degrees of path dependence. In the first-degree path dependence persistence of prior conditions or decisions exists but with no implied inefficiency. In the second-degree path dependence persistence of prior conditions or decisions leads to outcomes that are regrettable and costly to change. In the third-degree path dependence persistence leads to the outcomes that are inefficient but is remediable [7]. In the first and second-degree, the outcomes are not necessarily inefficient. But in all three degrees, the outcomes are remediable. It further implies that lock-in in a sense described by David and Arthur does not exist.

In theory, it is difficult to explain and prove the existence of lock-in. Still in practice, people, organizations and institutions remain locked in some technologies or solutions, although they are evidently inferior in comparison to other ones.

\section{Path Dependence and its Implications to Modern Business and Project Management}

Path dependence theory is applicable to various social sciences. Its application on any social science disciplines it requires multidisciplinary approach. However, when we talk about path dependence in business and management, we have to take into account market-orientation of the business on the whole. Behavior of interested parties on the market cannot be explained only from the point of view of economy and its benefits. It is often being caused by a number of factors from various cultural or historical circumstances to the simple behaviour of the consumers.

Here we should recall the premise "history matters" once more. The obvious question here is whether the history matters for modern business and management. Modern approaches to business do not usually take distant history seriously. In other words, modern managers concern only the events from recent past. However, the events from distant past are not very noticeable, but they can have long-time influence on modern behaviour and business. The most illustrious example is the one with QWERTY keyboard. This example is in details presented by Paul David in his work "Clio and the Economics of QWERTY". This example shows the power of lock-in effect over a long period of history. This and many other examples show that lock-in is key phenomenon related to path dependence in business and management. Lock-in in such cases may be defined as a consequence caused by various factors, among them:

- Technical interrelatedness, which represents the possibility to cope with existing infrastructure.

- The economy of scale, which can be regarded also as increasing returns and carries some benefits for both consumers and producers.

- Sunk costs, which have already been committed and cannot be recovered [8]

With lock-in effect explained above, path dependence can be also determined differently from the point of view of its implications to business. Then, path dependence can be regarded as characteristic of the resource that is developed through a unique series of events [9]. It means that such a resource is difficult or even impossible to copy by competitors and creates dependence on final products. Still, this implication is closely related to business and organizational strategy.

It is important to understand that strategies usually change gradually. The base of incremental development often lays in historical circumstances and cultural influences as well. If strategic solution in concern was successful in the past, there could be natural lack of wish to change it. The lack of wish to change usually leads to lock-in, while the environment keeps changing all the time. Consequently, form the organizational point of view, path regarded as a state where early events and decisions establish "policy paths" that have a crucial influence on subsequent events and decisions [10].

Talking about strategies and path dependence in strategy formation leads to institutional and organizational path dependence. Both institutional and organizational path-dependent processes are far more complex than technological ones. Factors with social, regulatory, political and cognitive nature gain more importance in institutional and organizational pathdependent processes. However, they are closely related to path dependence on technology. The competition between different technological solutions is not only 
about the very solutions but also about institutions and organizations promoting these solutions [11].

The main modification in observing path dependence from the point of view of organization or institution is their relation to the lock-in. The lock-in effect in technology is almost always related to inefficiency [12]. In the context of organizational studies, the locked-in solution is not necessarily inefficient at least in the beginning. On the other hand, inefficiency still is important feature of path-dependent processes at all. Institutions and organizations show high level of inertia. The policies, solutions and processes within an organization tend to demonstrate persistence, although environment changes. Such tendency creates potential for inefficiency. It is at least potential inefficiency that is worrying and makes path dependence a matter of high importance [13]. Like in original path dependence, related to technology, there are in organizational path dependence self-reinforcing mechanisms and positive feedback factors that facilitate creation of the lock-in effect in forming an organizational pattern. Hence, organizational path dependence can be thought of as rigidified potentially inefficient action pattern built up by the unintended consequences of former decisions and positive feedback processes [13].

Modern institutions and organizations show tendencies to be more flexible in decision-making processes. However, the flexibility depends on many factors such as regulatory environment, economic environment, level of knowledge as well as business culture of the organization's members.

The recently increasing number of organizations and institutions have been relying on projects as a special type of organizational form of activities. Projects are seen as temporary activities, with a wide range of flexible forms of organizing. Such flexible project-based organizing is considered totally opposite to strategic persistence and structural inertia [2].

As per definition of project stating that a project is a temporary endeavour undertaken to create a unique product, service or result [14]. Such characteristics as uniqueness and time limitations should imply the flexibility of activities within the project. More than that, projects are conceived as carriers of change. Still, projects are often organized in more complex structures. These structures can be in the form of networks or organizations. Oppositely from separate projects, such complex structures exhibit the need for stability and persistency. Under specific circumstances, the tendency for persistence may result in path dependence [2]. When put in context of project network, project ecology or simply activities of an organization, projects easily develop path-dependent processes through self-reinforcing mechanisms, and increasing returns of such environment.

\section{CLEAN ENERGY PROJECTS IN GROWING ECONOMIES}

Investment in renewable energy technologies is regarded as final stadium of implementation clean technology in modern industry. Many projects held under JI and CDM mechanisms under Kyoto Protocol, as well as its Carbon Trading Scheme, create pathdependent outcomes of such projects. The actors in CDM mechanisms usually fulfil their obligations by transferring technology to less developed countries where a certain project is implemented. In other words, such projects are related to minor advancements of incumbent dirty technologies or to mature renewable energy technologies [15]. In order to minimize the risk of full or partial failure, the companies-investors and carriers of project work usually choose to implement mature solutions in the projects that lead to pathdependent outcomes. More than that, governments of the countries that are direct users of CDM projects usually create their environmental policies to cope with Kyoto Protocol and CDM. Such is the case with Brazilian National Policy of Climate Change in 2009 (Portuguese acronym: PNMC). Through this legislation, in its Article 12, the country establishes a voluntary commitment to reduce from $36.1 \%$ to $38.9 \%$ the GHG emissions projected by 2020 [16].

However, one of the main triggers of pathdependent outcomes in renewable energy projects under Kyoto CDM mechanisms is trade-off. Kyoto CDM mechanisms offer a possibility of trading earned points through Carbon Trading Scheme. Such policy does not encourage projects that implement radical innovations or radical innovative models in the industry.

The CDM projects can be performed in the host countries that are not signees of Annex I of Kyoto Protocol. They can be performed by a project investor, which is a resident of the host country. If such project does not have any kind of support from foreign partners (i.e. financial, technology etc.), it can be considered unilateral project. CERs in these cases are issued to project developer. The developer further can transfer them to the investor via Carbon Trading Scheme.

Bilateral CDM projects include two parties. One of the parties, to be more precise the investor, must be from Annex I signee, while the developer is usually from the host country. Such projects usually are about technology transfer. In the vast majority of cases the investors transfer mature technology to the host country. CERs gained from bilateral investments are usually divided between the parties.

If a CDM project is funded by a multinational or international fund, it usually is multilateral. In the majority of cases, such funds commonly finance more than one similar projects. CERs than belong to the multinational investors that can divide them to other participants.

All three types of CDM projects create pathdependent outcomes. The strategy of unilateral projects is centred on path dependence, in which the host country develops technology, knowledge, routines and has an adequate institutional environment to explore the resources that are not easily shared and imitable [17]. Hence, the project investors and developers deliberately chose to make path-dependent outcomes in such projects, in order to protect their technology or 
knowledge from imitation. On the other hand, such projects result in routines and show serious inertia and resistance to change. In other words, the solutions become locked-in, and as time passes by, they become inefficient and persistent to change or replacement.

Bilateral CDM projects, especially the ones that imply the technology transfer, also exhibit path dependence. In such cases, path dependence is not the part of strategy of investor and developer. It rather is imposed by the investor from the Annex I country. The Annex I investors usually transfer mature and exhausted technology, often with used hardware. By implementing mature technology solutions, such projects produce path-dependent outcomes. The technology is locked-in to mature solution that is either inefficient from the beginning or is to become inefficient soon. Such solutions also become persistent to replacement and change.

Multilateral CDM projects are integrated into certain type of project networks since they are financed from one international or multinational institution. Project networks as wide project environment impose some persistence and stability. Such situations provoke the activity of self-reinforcing mechanisms of certain operations in every project that is usually transferred from one project to another or appear simultaneously in various projects. It happens because of more or less firm rules imposed by project network. As a result, multilateral CDM projects become less flexible.

Most probably such projects lead to the pat dependent outcomes as project results. The inefficiency in such cases can be developed during the very project. Multilateral CDM projects usually are large-scale projects form the point of view of both scope and financing. Such projects carry great risk and great number of tradeable CERs. In order to minimize risk, the organizations involved usually prefer to have certain stability that leads to creation of routines, persistency and even lock-in as a path-dependent outcome.

All the three types of CDM projects at least carry the potential of making path-dependent outcomes. The first type of projects deliberately produces pathdependent outcomes as a part of the strategy. The latter two types may produce path-dependent outcomes as side effect. Unilateral projects show the greatest level of flexibility since they are performed by residents of the host country. Nevertheless, since these projects mean the entry to the market with innovation, their most common business strategy ruling the project is producing non-imitable and unique product - i.e. pathdependent outcome. Bilateral projects are performed by investors from Annex I signees. Such projects show less flexibility because of the structure of stakeholders involved. All the stakeholders must cope with relevant local standards and legislation as well as with the international one in the face of the Kyoto Protocol and subordinate documents. The Annex I signees are usually countries with developed economies that invest in $\mathrm{R} \& \mathrm{D}$ projects in clean energy on their territories. In order to get rid of mature and old technology, they usually transfer it to host country. Such technology transfer usually creates path-dependent outcomes by self-reinforcing mechanisms and externalities in face of training and high switching costs. Multilateral projects show the least flexibility. They are usually organized to project networks since various projects with the same or similar goal are financed from the one source - the international or multinational fund. Possibility of appearance of path dependence here is very high since this project shows greater stability and persistency.

\section{CONCLUSIONS}

Path dependence recently became an interesting topic in economics and management. Dependence of evolution and development on one "historical accident" in [3] came into the focus of many studies of project management as well. Projects as flexible forms of organization are not expected to exhibit persistencies, routines or inertia that can lead to path dependence. On the other hand, under certain circumstances, even projects become persistent, seeking stability.

Concerning CDM projects related to clean energy and performed under the Kyoto protocol, they show great level of path dependence. The flexibility of CDM projects can be different - from unilateral projects with great flexibility to the multilateral projects financed by multinational or international institutions which show the lowest level of flexibility. All such projects have potential to produce path-dependent outcomes. Some of the projects deliberately chose such strategic approach in order to protect their production. Potential of creation of path-dependent outcomes even the appearance of path dependence itself in the project is imposed on other CDM projects. The reason for that is either acceptance of mature technology of actor from Annex I party or existence of the project in project network [2].

CDM projects under Kyoto Protocol programs create path-dependent outcomes due to the very nature of Kyoto Protocol and CDM mechanisms. Kyoto Protocol is too general and in many paragraphs rather unclear and ambiguous document. Through CDM and Carbon Trading Unit System Kyoto Protocol directly opens the door to the creation of path-dependent outcomes of CDM projects. In order to gain as many tradeable CERs as possible, project investors do not enter the R\&D projects because of the uncertainty of them and long time of development the final result. They rather try to get "quick and easy" CRUs instead.

Many host countries of CDM projects create regulatory environment that is at least ambiguous, unclear or even inappropriate for stimulating industry push of the projects.

More clear legislation that would stimulate the R\&D projects, protecting gained benefits and intellectual properties rights, as well as creation of new international mechanisms of support, that also should encourage investments in $\mathrm{R} \& \mathrm{D}$ projects, would increase competitive environment in green technologies of growing markets. 


\section{REFERENCES}

[1] M. I. Bodas Freitas, E. Dantas, and M. Iizuka, "The Global Institutional Frameworks and the Diffusion of Renewable Energy Technologies in the BRICS Countries", Maastricht: United Nations University - Maastricht Economic and Social Research and Training Centre on Innovation and Technology, 2010

[2] J. Sydow, "Path Dependence in Project Based Organizing Evidence from Television Production in Germany", Journal of Media Business Studies, 2010, pp. 123-139.

[3] P. David, "Clio and the Economics of QWERTY", American Economic Review vol. 75/2, Papers and Proceedings of the Ninety-Seventh Annual Meeting of the American Economic Association, 1985, pp. 332-337.

[4] P. David, "Path Dependence - A Foundational Concept of Historical Social Science", Oxford: University of Oxford, 2006

[5] S. E. Page, "Path Dependence", Quarterly Journal of Political Science, 2006, pp. 87-115.

[6] P. David, "Path Dependence, Its Critics and the Quest for Historical Economics", Cheltenham: Edward Elgar Publishing, 2000.

[7] S. J. Liebowitz, and S. E. Margolis, "Path Dependence, LockIn, and History", Journal of Law, Economics and Organization, vol. 11/1, 1995, pp. 205-226.

[8] N. G. Mankiw, "Principles of Economics", Mason: Thomson South Western, 2004

[9] G. G. Dess, G. T. Lumpkin, and A.B. Eisner, "Strategic Management: Text and Cases”, Boston: McGraw Hill, 2009.

[10] G. Johnson, K. Scholes, and R. Whittington, "Exploring Corporate Strategy", Harlow: Pearson Education Ltd, 2008.
[11] R. M. Nureev, "Russia After Crisis - Path Dependence Effect", "Rossiya posle krizisa - effekt kolei", Journal of Institutional Studies, 2010, pp. 7-26.

[12] W. B. Arthur, "Competing Technologies, Increasing Returns and Lock-in by Historical Events", Economic Journal, 1989 , pp. 116-131.

[13] J. Sydow, G. Schreyogg, and J. Koch, "Organizational Path Dependence: Opening the Black Box", Academy of Management Review, 2009, pp. 689-709.

[14] Project Management Institute, "A Guide to the Project Management Body of Knowledge (PMBOK Guide)", Newtown Square PA, USA: Project Management Institute Inc, 2008.

[15] P. Aghion, C. Hepburn, A. Teytelboym, and D. Zenghelis, "Path Dependence, Innovation and the Economics of Climate Change", London: Grantham Research Institute on Climate Change and Environment, 2014.

[16] C. Torres, R. K. Fermam, and I. Bragia, "CDM Projects in Brazil: Market Opportunity For Companies and New Designated Operational Entities", Ambiente \& Sociedade, 2016.

[17] S. L. Raimundini, and E. A. Pedrozo, "Analysis of the Brazilian Context for Clean Development Mechanism Projects under an Economic Perspective", International Journal of Business Innovation and Research, 2014, pp. 385-398. 